\title{
Influence du taux protéique et de la composition en acides aminés de l'aliment d'allaitement sur l'aminoacidémie de l'agneau préruminant
}

\author{
P. PATUREAU-MIRAND, M. THERIEZ *, J. PRUGNAUD et R. PION \\ avec la collaboration technique de F. BARRE et G. BAYLE \\ Laboratoire d'Étude du Métabolisme azoté, \\ * Station de Recherches sur l'Elevage des Ruminants, \\ Centre de Recherches de Clermont-Ferrand, I.N.R.A., \\ Theix - St-Genès-Champanelle \\ 63110 Beaumont (France)
}

\begin{abstract}
Résumé
L.étude de l'utilisation métabolique des acides aminés chez l'Agneau préruminant a été entreprise en déterminant l'évolution de l'urémie et de l'aminoacidémie selon le taux protéique de l'aliment d'allaitement, sa composition en acides aminés, l'âge de l'animal et le niveau d'allaitement. Trois aliments d'allaitement $(20,25$ et 30$)$ contenant respectivement environ 20,25 et 30 p. Ioo de matières azotées ainsi qu'un aliment $S$ supplémenté en méthionine, isoleucine, lysine et arginine sont distribués en quantités limitées ou à volonté à des agneaux préruminants au cours de 2 essais. L'urémie et l'aminoacidémie post-prandiales sont déterminées à 8 et $2 \mathrm{I}$ jours. A âges et niveaux d'alimentation donnés, l'urémie augmente en fonction de la quantité d'azote ingérée et du taux protéique de l'aliment. Elle est plus élevée chez les agneaux de 2 I jours recevant les aliments 20 et 25 en quantité limitée que chez ceux qui sont nourris à volonté. Les urémies des agneaux de 8 et 2 r jours sont voisines. Les teneurs en acides aminés libres du sang augmentent avec le taux protéique du régime à 8 et 2 I jours; les concentrations sanguines en la plupart des acides aminés indispensables sont d'autant plus élevées que leurs teneurs dans l'aliment sont fortes. Pour un régime donné, les teneurs sanguines en acides aminés indispensables libres sont relativement voisines dans le sang des agneaux de 8 et 2 I jours, nourris à volonté ou rationnés. La supplémentation en méthionine, isoleucine, lysine et arginine d'une part améliore la rétention azotéc, d'autre part se traduit par une réduction de l'urémie et des teneurs en la plupart des acides aminés indispensables. L'examen des variations de la teneur en méthionine libre en fonction de la quantité ingérée par jour indique que le besoin de l'agneau préruminant entre 8 et $2 \mathrm{I}$ jours est proche de $2,0 \mathrm{~g}$ par jour (soit 2,6 g par jour d'acides aminés soufrés).
\end{abstract}

\section{Introduction}

Parmi les travaux consacrés à la nutrition azotée de l'Agneau préruminant. la plupart décrivent l'influence de la teneur en matières azotées des aliments d'allaitement sur la consommation, la croissance et la rétention azotée des agneaux 
ainsi que la digestibilité de l'aliment (Walker et Faicheney, 1964; Norton et Walker, r97I; Walker et Norton, i97I; Black, Pearce et Tribe, I973; Chiou et Jordan, I973; Walker et Kirk, I975). Seuls Bergen et PotTer (I975) ont étudié l'influence du taux azoté de la ration sur l'aminoacidémie post-prandiale des agneaux. Ce critère qui, chez les Monogastriques, dépend en partie de la quantité de protéines ingérée, de leur composition en acides aminés et de leur utilisation digestive et métabolique (MUNRo, I970), peut permettre d'apprécier l'état de satisfaction du besoin en certains acides aminés indispensables et leur disponibilité dans les protéines ingérées (Pion, I976). Potter, Purser et Bergen (I972), Patureau-Mirand, Theriez et Prugnaud (I975) ont déjà montré que, chez l'Agneau préruminant, comme chez les Monogastriques, l'aminoacidémie post-prandiale dépend de la composition en acides aminés de l'aliment.

Aussi nous avons étudié l'utilisation métabolique des acides aminés chez l'Agneau préruminant en déterminant l'évolution de l'urémie et de l'amino acidémie post-prandiale selon le taux protéique de l'aliment d'allaitement, sa composition en acides aminés, l'âge de l'animal et le niveau d'alimentation. Cette étude, effectuée avec les mêmes aliments et les mêmes animaux, complète les travaux de Theriez, Patureau-Mirand et Molenat (I977) qui rapportent l'influence de ces 4 facteurs sur la consommation et la digestibilité de l'aliment, la croissance et le bilan azoté des agneaux.

TABLEAU I

Composition des aliments d'allaitement Composition of the diets

\begin{tabular}{|c|c|c|c|c|c|c|c|}
\hline $\begin{array}{l}\text { Aliments } \\
\text { Diets }\end{array}$ & \multicolumn{2}{|c|}{20} & \multicolumn{2}{|c|}{25} & \multicolumn{2}{|c|}{$3^{\circ}$} & $\mathrm{S}$ \\
\hline 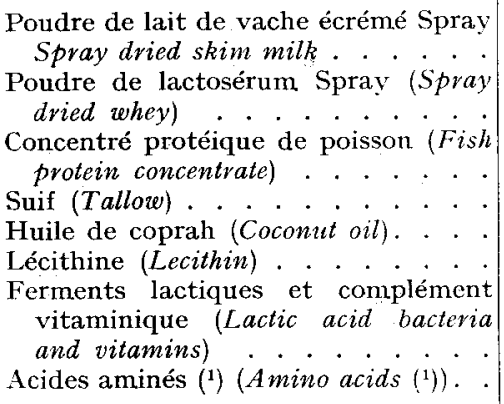 & & $\begin{array}{l}.0 \\
5 \\
5\end{array}$ & $\begin{array}{r}9 \\
16 \\
9 \\
1\end{array}$ & $\begin{array}{l}0 \\
0 \\
0\end{array}$ & $\begin{array}{r}10 \\
15 \\
8 \\
\text { I }\end{array}$ & & $\begin{array}{r}70,25 \\
- \\
2,0 \\
15,0 \\
8,5 \\
1\end{array}$ \\
\hline Essais (Trials) . . . . . . . . . . & I & 2 & I & 2 & I & 2 & I \\
\hline $\begin{array}{c}\text { Matières azotées }(\mathrm{N} \times 6,25 \% \mathrm{MS}) \\
\text { Crude protein }(N \times 6.25 \% D M)\end{array}$ & 22,2 & 20,6 & 26,4 & 25,3 & 31,8 & $3 \mathrm{I}, 5$ & 28,8 \\
\hline 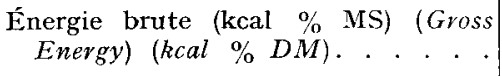 & $55^{6}$ & $53^{\circ}$ & 566 & 537 & 564 & 545 & 557 \\
\hline
\end{tabular}

(1) DL-Méthionine : 0,25; L-Isoleucine : o,03; L-Lysine $\mathrm{HCl}: 0 ; 37 ;$ L-Arginine : 0,10 . 


\section{Matériel et méthodes}

$$
\text { I. - Animaux }
$$

Deux essais ont été entrepris sur des agneaux Limousins ou croisés Romanov $\times$ Limousins au stade préruminant. Les agneaux de l'essai I sont placés en cases individuelles de sorte que la consommation individuelle d'aliment peut être mesurée; en revanche, ceux de l'essai 2 sont élevés en lots et seule la consommation moyenne par lot peut être déterminée.

TABLEAL 2

Composition (") en acides aminés des matières azoties des aliments Amino acid composition (1) of the dietary proteins

(g p. $16 \mathrm{gN}$ )

\begin{tabular}{|c|c|c|c|c|c|c|c|}
\hline $\begin{array}{l}\text { Aliments } \\
\text { Diets }\end{array}$ & & & & 20 & 25 & 30 & $\mathrm{~S}$ \\
\hline Ac. aspartique & . & . & . & 8,5 & $8,2.5$ & $8, \mathrm{I}$ & 7,75 \\
\hline THREONINE. & . & • & $\cdot$ & 4,65 & 4,5 & 4,35 & 4,45 \\
\hline Sérine. . . & & • &. & 4.95 & 5,25 & 5,4 & 5.55 \\
\hline Ac. glutamique & & . & . & 17,0 & 18.7 & I 9,85 & $2 \mathrm{I}, 4$ \\
\hline Proline . . . & & . &. & 6,65 & 7,7 & 8,4 & 9,3 \\
\hline Glycine . . & & . &. & 4,3 & 3,9 & 3.7 & 2,35 \\
\hline Alanine . . & . & . & $\cdot$ & +.7 .5 & 4.45 & 4,25 & 3.6 \\
\hline VALINE & . & . & . & 5.5 .5 & 6.05 & 6,35 & 6,8 \\
\hline CYSTINE. . . & & . & $\cdot$ & 1,0 & 0,95 & 0,85 & 0,85 \\
\hline Miethionine . & & . &. & $2,3.5$ & 2,5 & 2,55 & 3,45 \\
\hline ISOLEUCINE . & & . &. & 4,85 & $.5,05$ & 5,15 & 5,55 \\
\hline I.EUCINE . & & . &. & $8, \mathbf{I}$ & 8,6 & 8,9 & 9.5 \\
\hline TYROSINE . . & & . & .1 & 3,4 & 3,95 & 4,35 &,+ 8 \\
\hline PHENYLALANINE & & . & . & 3,9 & 4.35 & 4,7 & 5,05 \\
\hline I,YSINE $\cdot \cdot$ & & . & .1 & 8,0 & 8,15 & 8,25 & 9,35 \\
\hline HISTIDINE . & & . & & 2,2 & 2.5 & 2,65 & 2,75 \\
\hline ARGININE & & . &. & $4,2.5$ & 4.25 & $4,3.5$ & t,o \\
\hline TRYPTOPHANE & & . &. & $1, O$ & 1,0 & 1,0 & $\mathrm{I}, \mathrm{I}$ \\
\hline
\end{tabular}

(1) Calculce d'apris la composition de l'aliment et les teneurs en acides aminés de ses constituants protéiques. (Calculated from the composition of the dicts and the amino acid composition of dietary proteins.)

\section{2. - Aliments}

L'étude de l'influence du taux protéique de l'aliment d'allaitement sur le métabolisme azoté des agneaux a été réalisée à l'aide de 3 aliments (tabl. I) (20, 25 et 30$)$, de taux protéique croissant. La composition en acides aminés des matières azotées de ces 3 aliments est sensiblement la même.

Afin d'apprécier l'influence de la composition en acides aminés des matières azotées alimentaires, un quatrième aliment (S) a été utilisé (tabl. I). Les protéines 


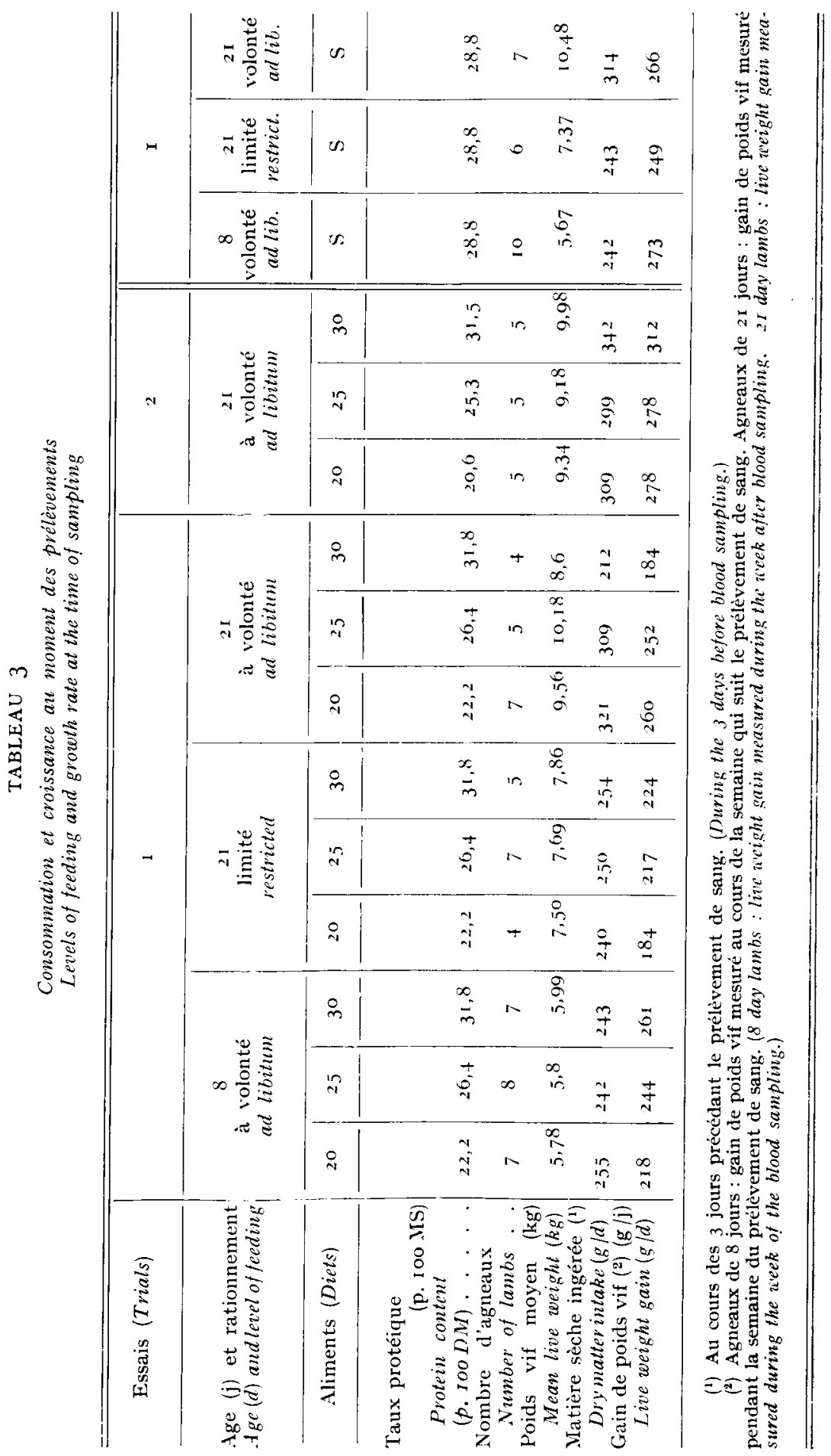


de cet aliment sont principalement des protéines de lait de vache supplémentées en méthionine, isoleucine, lysine et arginine de façon à obtenir une composition en acides aminés indispensables voisine de celle du lait de brebis légèrement enrichi en méthionine (tabl. 2).

\section{3. - Schéma expérimental, prélèvements et dosages}

Dans l'essai I, les agneaux sont répartis en 4 lots de I6 agneaux selon les 4 aliments 20, 25, 30 et $\mathrm{S}$. A partir de l'âge de 3 jours, 8 agneaux par lot sont rationnés selon le protocole décrit par Theriez, Patureau-Mirand et Molenat (i977) et dans lequel sont précisées les conditions de mesure du bilan azoté au cours de la $2^{\mathrm{e}}$ et de la $3^{\mathrm{e}}$ semaine d'âge des agneaux. Les prélèvements de sang jugulaire pour le dosage de l'urée et des acides aminés libres sont effectués aux âges moyens de 8 et $2 \mathrm{I} j$, vers I 4-I $5 \mathrm{~h}$, soit $4-5 \mathrm{~h}$ après la distribution d'aliment du matin, sur les agneaux qui ont ingéré plus de $400 \mathrm{~g}$ d'aliment liquide dans la période d'environ I h 30 qui suit cette distribution. Dans l'essai 2, les agneaux sont alimentés à volonté. Les prélèvements de sang sont effectués dans chacun des 3 lots, sur 5 agneaux d'un âge moyen de $2 \mathrm{I}$ j dont l'appétit est satisfaisant. Dans les 2 essais après avoir été mis à la disposition des animaux le matin pendant $\mathrm{I} h \mathrm{~h}$ \%, l'aliment est retiré pendant $3 \mathrm{~h}$ en attendant les prélèvements.

L'urémie est mesurée dans le sang de chaque animal alors que les acides aminés libres du sang sont dosés sur un échantillon moyen constitué par le mélange des fractions aliquotes de sang prélevées sur les animaux recevant le même régime. Les méthodes de dosage de l'urée et des acides aminés du sang ont été décrites précédemment (Patureau-Mirand, Prugnaud et Pion, i973). Les performances des agneaux au moment des prélèvements (tabl. 3) indiquent que les animaux sont en bonne santé, à l'exception de ceux de $2 \mathrm{I} \mathrm{j}$ nourris à volonté avec l'aliment 30 dans l'essai I. L'urémie et l'aminoacidémie des agneaux de ce lot n'ont pas été rapportées.

\section{Résultats}

\section{A. -- Influence du taux protéique}

\section{Urémie}

L'urémie s'élève avec le taux protéique de l'aliment mais dépend aussi de la quantité d'azote ingérée. En effet, l'urémie $y$ (mg p. Ioog de sang) peut être liée à la quantité d'azote ingérée $x(\mathrm{~g} / \mathrm{j})$ par la relation $y=2,56 x+\mathrm{I}, 50 ; r=0,66$; $\mathrm{S} x y=7,8$. De façon à mieux préciser l'influence du taux protéique, les urémies mesurées pendant l'essai I ont été ajustées par covariance selon la quantité d'azote ingérée par jour (tabl. 4). Les urémies des agneaux de $8 \mathrm{j}$ augmentent de façon significative avec le taux protéique des régimes. A 2 I $\mathrm{j}$ parmi les agneaux rationnés, l'urémie des agneaux qui consomment l'aliment 20 est significativement inférieure à celle des agneaux des 2 autres lots et chez les agneaux nourris à volonté elle est aussi significativement inféricure à celle des animaux du lot 25 .

Les urémies des agneaux de $8 \mathrm{j}$ ou de $2 \mathrm{I}$ j nourris à volonté avec les aliments 20 et 25 sont voisines et inférieures à celles des agneaux rationnés qui reçoivent les mêmes aliments. Avec l'aliment 30 , les urémies des agneaux âgés de 8 j sont supérieures à celles des agneaux rationnés de $2 \mathrm{I}$ j. 
TABLEAU 4

Urémies ( $m g \% g$ de sang)

Blood urea ( $m$ g \% g blood)

(moyennes $\pm S x) \ldots($ mean $\div S x)$

\begin{tabular}{|c|c|c|c|c|c|}
\hline $\begin{array}{l}\text { Age et rationnement } \\
\text { (A ge and level of feeding) }\end{array}$ & $\begin{array}{r}\text { Régin } \\
\text { Essais } \\
(\text { Trials })\end{array}$ & 20 & 25 & 30 & $\mathrm{~S}$ \\
\hline $\begin{array}{l}8 \text { jours nourris à volonté } \\
(8 \text { days ad libitum })\end{array}$ & I (1) & $20, \mathrm{I} \pm 2,3^{a}$ & $26,0 \pm 2,0^{b}$ & $44,3 \therefore 2,2^{c}$ & $3^{I, I} \pm \mathbf{I}, 8^{b}$ \\
\hline $\begin{array}{l}2 \text { I jours nourris à vo- } \\
\text { lonté }(2 I \text { days ad libi- } \\
\text { tum }) \cdot . \cdot . \cdot .\end{array}$ & $\begin{array}{l}1 \\
2\end{array}$ & $\begin{array}{l}20,9 \pm 2,3^{a} \\
20,3 \pm 2,0^{a}\end{array}$ & $\begin{array}{l}28,4 \pm 2,6^{b} \\
28,3 \pm 1,4^{b}\end{array}$ & $47,9 \pm 2,5^{c}$ & $34,8 \pm 2,4^{b}$ \\
\hline $\begin{array}{l}21 \text { jours rationnés (2I } \\
\text { days restricted). . . }\end{array}$ & I & $26,4+2,7$ & $33,8 \pm 2,2^{b}$ & $3^{8,6} \doteq 2,6^{b}$ & $32.5 \pm 2,2^{a b}$ \\
\hline
\end{tabular}

(1) Les urémies mesurées au cours de l'essai I ont été ajustées par covariance sur l'ensemble des agneaux selon la quantité d'azote ingérée par jour. (Blood levels of urea measured during trial $I$ are adjusted according to the amount of nitrogen ingested.)

${ }^{(2)}$ L,es valeurs d'une même ligne affectées de la même lettre ne sont pas significativement différentes $(\mathrm{P}>0,05)$. (Values followed by the same letter are not significantly different $(P>0,05)$.)

\section{Aminoacidémie}

Les teneurs en acides aminés libres du sang augmentent avec le taux protéique des régimes (tabl. 5); cela résulte de l'augmentation importante de la plupart des teneurs en acides aminés indispensables, très supérieure à celle des teneurs en acides aminés non indispensables. Les concentrations sanguines en valine, méthionine, isoleucine, leucine, tyrosine, phénylalanine et lysine augmentent avec le taux protéique ou la teneur de l'aliment en ces composés chez les agneaux de $8 \mathrm{j}$ comme chez ceux de 2 I j rationnés ou nourris à volonté pendant les 2 essais. Cette augmentation est sensiblement linéaire. Les teneurs en thréonine ne varient dans le même sens que la teneur de l'aliment en cet acide aminé, que dans le sang des agneaux de $2 \mathrm{I} \mathrm{j}$. Les teneurs sanguines en histidine et arginine ne semblent pas dépendre directement du taux protéique des régimes ou de leur concentration en ces composés.

Parmi les acides aminés non indispensables, seules les concentrations en sérine et proline libres du sang augmentent régulièrement en fonction de leur teneur dans l'aliment (tabl. 6); les teneurs sanguines en glutamine (+ asparagine) etornithine s'élèvent en fonction du taux protéique de l'aliment chez les agneaux de $2 \mathrm{I} j$ de même que celles en citrulline des agneaux de $8 \mathrm{j}$; les concentrations sanguines en acide glutamique et alanine varient peu.

\section{B. - Influence de la composition en acides aminés des matières azotées alimentaires}

Les matières azotées du régime $S$ sont plus riches en tous les acides aminés indispensables (à l'exception de l'arginine) que celles des régimes 25 et 30 . Cependant l'équilibre en acides aminés indispensables et semi-indispensables est sensi- 


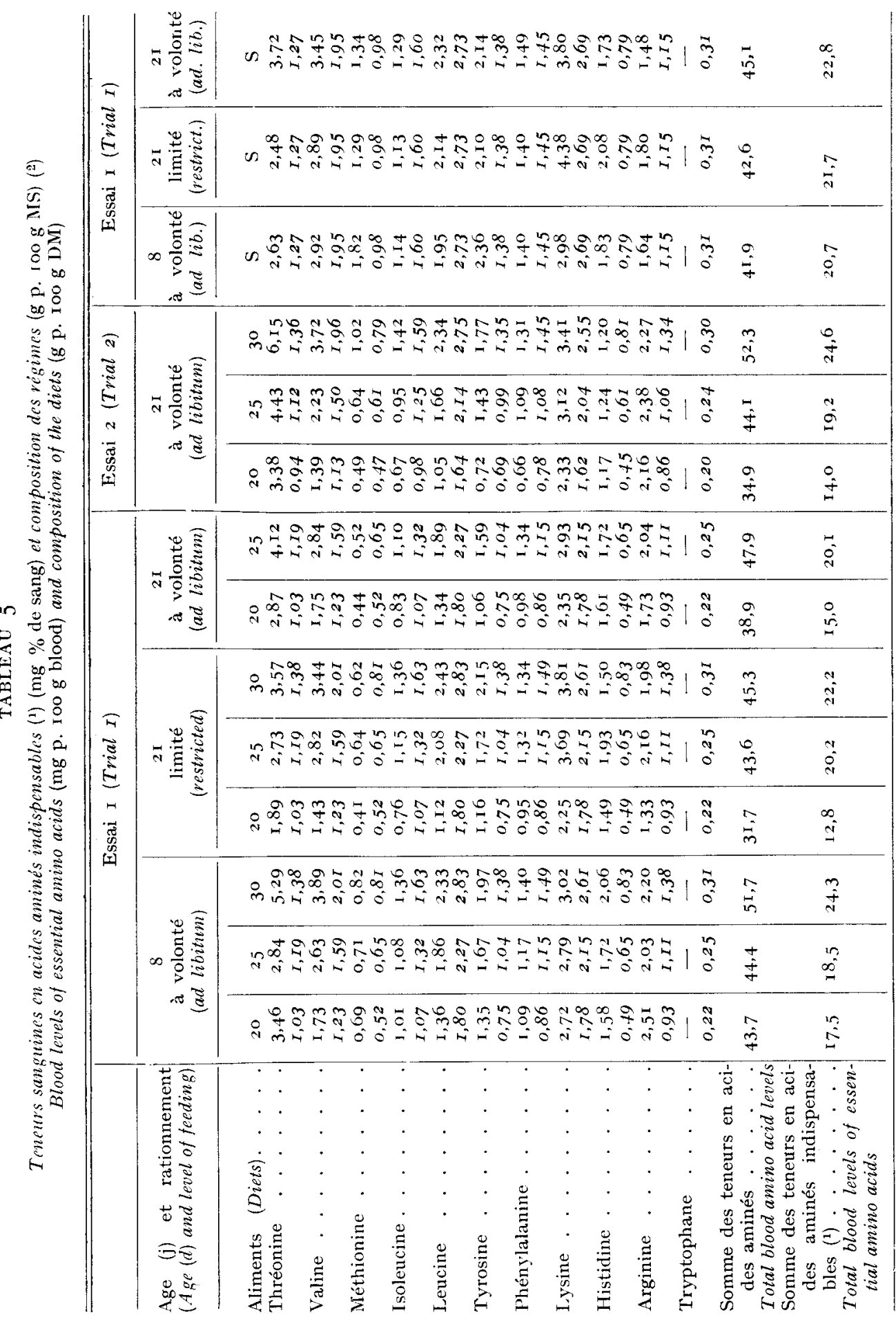




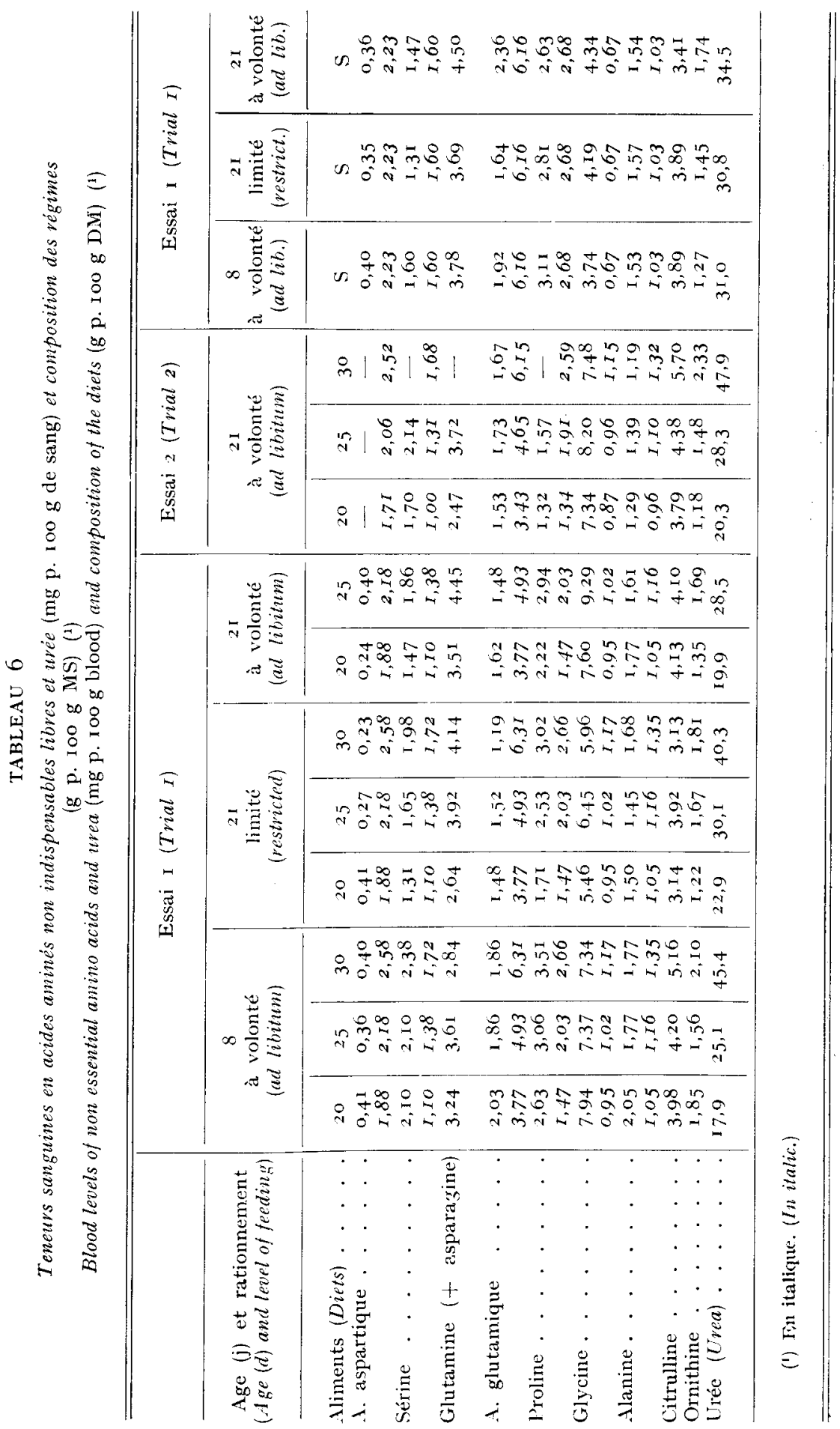


blement le même dans ces 3 régimes; seuls les acides aminés soufrés et l'arginine se trouvent respectivement en proportion plus forte $(+12 \%)$ et plus faible (- I5\%) dans le régime $\mathrm{S}$ que dans les 2 autres régimes.

\section{Urémie (tabl. 4)}

L'urémie des agneaux de $8 \mathrm{j}$ consommant l'aliment $\mathrm{S}$ est supérieure mais de façon non significative à celle des agneaux du lot 25; en revanche, elle est significativement inférieure à celle des agneaux du lot 30 . A 2 I j, l'urémie des agneaux rationnés du lot $\mathrm{S}$ n'est pas significativement différente de celle des agneaux des lots 20 et 25 mais aussi 30 .

Les urémies des agneaux qui consomment l'aliment $S$, à 8 j ou à 2 I j rationnés ou non, ne sont pas significativement différentes.

\section{Aminoacidémie}

La supplémentation en méthionine, lysine, isoleucine et arginine a des effets différents selon les acides aminés (tabl. 5). Ainsi la méthionine s'accumule dans le sang des agneaux de 8 ou 2 i j rationnés ou non. Les courbes qui décrivent l'évolution de la teneur en méthionine libre du sang en fonction de la quantité journalière ingérée (fig. I) présentent une certaine similitude quel que soit l'âge ou le rationnement. La supplémentation en lysine ne s'est manifestée par une augmentation sensible des teneurs sanguines en ce composé que chez les agneaux de 2 I $\mathbf{j}$ (rationnés ou non). En revanche, bien que la supplémentation en isoleucine ait relevé la concentration de l'aliment $\mathrm{S}$ à un niveau voisin de celle de l'aliment 30 , les teneurs en isoleucine libre sont plus faibles dans le sang des agneaux qui irgèrent l'aliment $\mathrm{S}$ que dans celui de ceux qui reçoivent l'aliment 30. De la même façon, les teneurs en arginine du sang des agneaux qui ingèrent le régime $S$ restent inférieures à celles des agneaux nourris avec l'aliment 25 bien que les concentrations en arginine de ces 2 régimes soient très voisines.

L'influence de la supplémentation semble aussi s'être manifestée sur les teneurs en d'autres acides aminés indispensables (tabl. 5). Ainsi les teneurs en thréonine et valine sont généralement supérieures dans le sang des agneaux qui consomment les aliments 25 et 30 dont la teneur en ces composés est inférieure ou égale à celle de l'aliment $\mathrm{S}$. Une même tendance s'observe pour la leucine chez les agneaux de 8 j ou ceux de 2 I j rationnés.

Si parmi les acides aminés non indispensables (tabl. 6), les faibles concentrations en glycine du sang des agneaux nourris avec l'aliment $\mathrm{S}$ correspondent à la faible teneur en glycine de ce régime, il n'en est pas de même pour la sérine dont cet aliment est riche. En outre, les concentrations en citrulline du sang de ces agneaux sont les plus faibles.

\section{Discussion}

\section{I. - Infuence du taux protéique}

Si l'augmentation du taux protéique du régime n'a que peu d'influence sur la vitesse de croissance, elle s'accompagne néanmoins, d'un accroissement du bilan azoté (Theriez, Patureau-Mirand et Molenat, I977) et d'une modification de l'urémie et de l'aminoacidémie. L'augmentation des teneurs sanguines en acides aminés indispensables libres, déjà décrite par BERGEN et PotTer (I975), 
qui traduit une moindre efficacité de l'utilisation de ces composés par l'organisme, et l'accroissement de l'urémie qui reflète un catabolisme accru des acides aminés, contribuent à expliquer la baisse de l'efficacité de la rétention azotée que nous avons observée après BLACK, PEARCE et TRIBE (I973), chez l'Agneau préruminant, lorsque le taux protéique de la ration s'élève. L'augmentation des teneurs sanguines

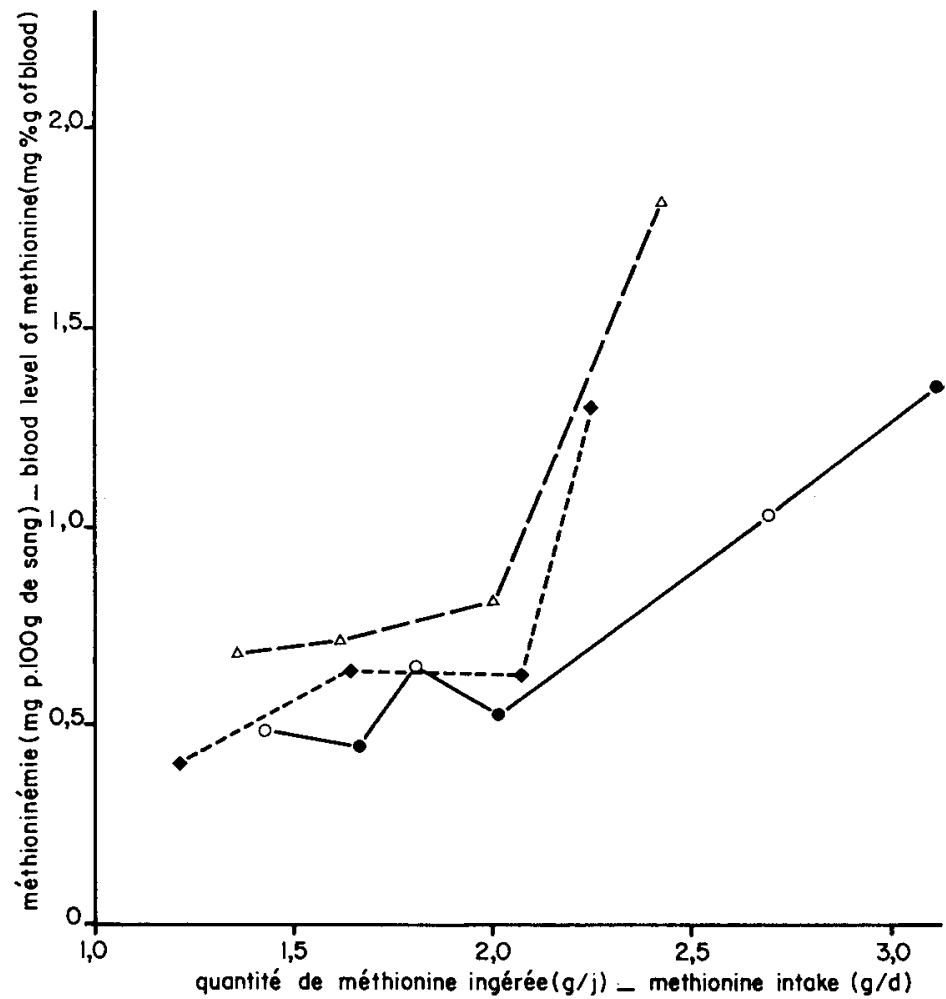

FIG. 1. Évolution de la méthioninémie en fonction de la quantité de méthionine ingérée Blood level of methionine according to methionine intake.

- Agneaux de 8 jours $(8$-day lambs).

- Agneaux de $2 \mathrm{r}$ jours nourris à volonté, essai r (2 I-day lambs fed ad libitum, trial I).

- Agneaux de $2 \mathrm{I}$ jours nourris à volonté, essai 2 (2I-day lambs fed ad libitum, trial 2 ).

- Agneaux de $2 \mathrm{I}$ jours rationnés (2I-day lambs, restricted).

en urée et ornithine en fonction du taux protéique du régime, ainsi que la baisse du rapport des teneurs en citrulline à celle en ornithine ou de celle en ornithine à celle en urée, chez les agneaux de $2 \mathrm{I} j$, semblent témoigner de l'influence du taux protéique de la ration sur l'activité des enzymes du cycle de l'urée telle qu'elle a été décrite par Schimke (I962) et Das et Waterlow (I974).

\section{2. - Influence du rationnement}

L'influence du rationnement se manifeste à $2 \mathrm{I} \mathrm{j}$ au niveau sanguin par une urémie des agneaux nourris avec les régimes 20 et 25 , supérieure à celle des animaux de même âge nourris à volonté. Cela semble indiquer que la restriction éner- 
gétique s'accompagne d'un catabolisme accru des acides aminés correspondant à une utilisation énergétique de ces composés comme cela a déjà été observé chez le Rat soumis à une restriction énergétique (ARNAL, Fauconneau et Pech, 1972; GRIZARD et al., I975). Les résultats observés dans le cas de l'aliment 30 où les. urémies des agneaux nourris à volonté sont supérieures à celles des agneaux rationnés ne sont pas incompatibles avec les observations précédentes si, pour les performances observées, l'écart entre le besoin énergétique des agneaux nourris à volonté et celui des rationnés est proportionnellement plus important que l'écart entre les quantités d'azote ingérées par les agneaux de ces 2 lots.

Les teneurs en la plupart des acides aminés sont voisines, pour un régime donné, dans le sang des agneaux rationnés ou nourris à volonté, à l'excep-. tion de celles en thréonine et en glycine qui sont supérieures chez les agneaux. nourris à volonté. Cela peut correspondre à l'ingestion d'une plus grande quantité de ces acides aminés (en particulier dans le cas de la glycine dont les quantités ingérées par les agneaux nourris à volonté sont élevées et semblent provoquer une accumulation de ce composé dans le sang) ou un catabolisme plus important chez. les agneaux rationnés que chez ceux qui sont nourris à volonté.

\section{3. - Influence de l'âge}

La similitude des valeurs de l'urémie des agneaux nourris à volonté à 8 ou à: 2 I $\mathrm{j}$ suggère que l'intensité du catabolisme des acides aminés est analogue à ces. 2 âges. L'évolution, quelque peu différente en fonction du taux protéique des. teneurs sanguines en citrulline et ornithine, à ces 2 âges, peut correspondre à l'évolution particulière en fonction de l'âge de l'activité des diverses enzymes du cycle de l'urée chez le jeune animal. Kaplan et Pitot (I970) rapportent en effet que chez le jeune rat, les activités de la carbamyl phosphate synthétase, de l'ornithine trans-carbamylase et de l'argininosuccinate synthétase augmentent après la naissance..

\section{4. - Influence de la supplémentation en acides aminés}

Il n'y a pas de régime témoin absolument comparable à l'aliment S. En effet, ce dernier diffère légèrement des régimes 25 ou 30 par la composition en acides. aminés de ses matières azotées, par la nature de ses protéines et par son taux pro-. téique. Il est toutefois possible de tenir compte d'une éventuelle influence de ce dernier facteur en comparant les résultats observés avec ceux obtenus avec les aliments 25 et 30 .

L'utilisation de l'aliment $\mathrm{S}$ dont l'équilibre en acides aminés indispensables était différent de celui des autres aliments et en principe plus favorable, n'a pas amélioré la vitesse de croissance ou l'efficacité alimentaire. Elle a cependant permis une amélioration du bilan azoté, particulièrement sensible à 2 semaines, car il est égal à celui obtenu avec l'aliment 30 et supérieur à celui observé avec l'ali-. ment 25. Ce résultat peut être rapproché de celui de WaLKER et KIRK (I975) qui signalent que la supplémentation en méthionine d'un régime contenant $28 \mathrm{p}$. Ioo de matières azotées permet une amélioration de la rétention azotée sans augmentation de la vitesse de croissance chez des agneaux préruminants de $9 \mathrm{~kg}$. La supplémentation en acides aminés n'a pas eu d'effet très net sur l'urémie. Toutefois, celle-ci n'est jamais significativement différente de celle des agneaux qui consomment l'aliment 25 et, à $8 \mathrm{j}$, elle est significativement inférieure à celle des. 
agneaux nourris avec le régime 30 . Cela concorde avec le fait que le coefficient de rétention azotée des agneaux du lot $\mathrm{S}$ à 2 semaines est significativement supérieur à celui des agneaux du lot 30 mais non différent de celui des agneaux des lots 20 et 25 .

L'influence de la supplémentation est plus nette encore sur les teneurs en acides aminés libres du sang. Les courbes d'évolution de la méthioninémie (fig. I) montrent que lorsque les quantités de méthionine ingérées sont supérieures à $2 \mathrm{~g} / \mathrm{j}$, l'apport excède les possibilités d'utilisation par l'organisme puisque ce composé tend à s'accumuler dans le sang. L'apport optimal de méthionine serait voisin ou légèrement supérieur à $2 \mathrm{~g} / \mathrm{j}$ (soit 2,6 $\mathrm{g}$ d'acides aminés soufrés). Ce résultat, en accord avec les bilans azotés élevés observés avec les aliments $S$ et 30 , concorde avec les résultats de WALKER et KIRK (I975) qui constatent que le bilan azoté d'agneaux ingérant 2,o g d'acides aminés soufrés par jour est significativement inférieur à celui des animaux qui en ingérent 3,3 g. L'absence d'effet de la supplémentation en méthionine sur la vitesse de croissance, alors que le bilan azoté est augmenté, peut en partie s'expliquer par un accroissement de la rétention d'azote dans la toison et une composition corporelle différente puisque selon WALKER (I975), la supplémentation en méthionine d'un régime pauvre en protéines de lait ( $2 \%$ ) accroît la pousse de la laine et diminue la teneur corporelle en lipides. Les teneurs relativement élevées en lysine libre du sang des agneaux de ${ }_{2}$ j j recevant l'aliment $S$ indiquent que l'apport est excessif pour des animaux de cet âge alors qu'à $\delta$ j il ne l'est pas. En revanche, les teneurs en isoleucine et arginine du sang de tous les agneaux recevant l'aliment $S$ qui sont relativement basses montrent que la supplémentation en ces composés n'a pas été excessive. L'influence de la supplémentation, en méthionine en particulier puisque c'est le seul acide aminé qui ait été apporté de façon certaine en quantité égale ou légèrement supérieure au besoin dans tous les cas, s'est manifestée sur l'utilisation des autres acides aminés indispensables. Ainsi les teneurs sanguines en thréonine, valine, isoleucine et arginine, inférietres chez tous les agneaux nourris avec l'aliment $S$ à celles des agneaux alimentés avec les régimes 25 ou 30 qui en contiennent des quantités équivalentes, permettent de penser que l'utilisation de ces composés a été accrue par la supplémentation.

\section{Conclusion}

L'augmentation des teneurs en la plupart des acides aminés indispensables et de l'urée dans le sang des agneaux qui ingèrent des aliments à taux protéique croissant, indique que, lorsque l'apport excède les possibilités d'utilisation, ces composés s'accumulent et qu'une fraction croissante des acides aminés ingérés est catabolisée. Ce phénomène s'observe à $8 \mathrm{j}$ comme à $2 \mathrm{I} \mathrm{j}$ chez les agneaux nourris à volonté ou rationnés. En outre, il semblerait que l'amélioration du bilan azoté et de l'utilisation métabolique des acides aminés observée chez les agneaux qui ingèrent l'aliment $S$, résulte en grande partic de la richesse de ce régime en méthionine. Le besoin en acides aminés soufrés de l'agneau préruminant, entre 8 et $2 \mathrm{I} \mathrm{j}$, apprécié par l'étude de la rétention azotéc ou de la méthioninémie en fonction de l'apport de méthionine serait proche de $2,6 / \mathrm{j}$. 


\section{Summary}

\section{Influence of the protein content and amino acid composition of the diets on the blood levels of free amino acids in preruminant lambs}

Protein metabolism in young preruminant lambs was studied by determining the influence of the dietary protein content and amino acid composition on the blood levels of urea and free amino acids. The animals aged between 8 and $2 \mathrm{I}$ days were subjected to two feeding levels. Three diets $(20,25$ and 30 ) containing about 20,25 and 30 per cent crude protein (Table I) were offered ad libittim or in restricted amounts (about $85 \%$ of the amounts ingested by the lambs fed ad libitum) during trials I and 2 . In addition, diet S containing 29 per cent crude protein supplemented with methionine, isoleucine, lysine and arginine was given to lambs of trial I (Table I). Post-prandial jugular blood levels of urea and of free amino acids were measured when the lambs were 8 and 21 day old.

Increase in the crude protein intake or in the protein content of the diets increased the blood level of urea (Table 4); it was higher in the blood of the restricted 21 day-old lambs fed diets 20 and 25 than in the ad libitum fed lambs of the same age. Blood levels of urea in the ad libitum fed 8 and 21 day-old lambs were similar. Blood levels of free amino acids (Tables 5 and 6) and especially most of the essential amino acids increased when the amino acid content of the diets rose. They were similar in the restricted or ad libitum fed 8 and 2 I day-old lambs. Blood levels of urea and of most of the essential amino acids were either lower or slightly higher in lambs fed diet $\mathrm{S}$ than in those fed diet 25 although the amount of crude protein or amino acids ingested was higher. Mieasurement of the blood level of methionine according to methionine intake (fig. I) showed that the requirement for this amino acid in the 8 to $2 \mathrm{I}$ day-old preruminant lamb ranged about $2.0 \mathrm{~g} /$ day, i.e. $2.6 \mathrm{~g}$ sulphur amino acids per day.

\section{Références bibliographiques}

Arnal M., Fauconneau G., Pech R., I972. Synthèses protéiques in vivo dans divers tissus du Rat en croissance soumis à une restriction de l'apport énergétique. Ann. Biol. anim. Bioch. Biophys., 12, 9I-IO8.

Bergen W. G., Potter E. L., I975. Effect of dietary protein level on plasma and tissue free amino acid concentrations in nursing lambs. J. Anim. Sci., 40, 789-794.

Black J. L., Pearce G. R., Tribe D. E., 1973. Protein requirements of growing lambs. $B r$. J. Nitr., 30, 45-6o.

Chiou P. W. S., Jordan R. M., I973. Ewe milk replacer diets for young lambs. I. Effect of age of lamb and dietary fat on digestibility of the diet, nitrogen retention, and plasma constituents. I. Anim. Sci, 36, 597-603.

DAS T. K., WATERLOW J. C., I974. The rate of adaptation of urea cycle enzymes, aminotransferases and glutamic deshydrogenase to changes in dietary protein intake. $B r . J . N u t r ., 32$, 353-373.

Grizard J., Prugnaud J., Arnal M., Pion R., I975. Effet de l'insuline sur la composition corporelle et les teneurs en acides aminés libres du sang, du foie et du muscle du rat en croissance soumis à une restriction énergétique. Ann. Biol. anim. Bioch. Biophys., 15, 569-582.

Kaplan J. H., Pitot H. C., I970. The regulation of intermediary amino acid metabolism in animal tissues. In Munro H. N. Mammalian protein metabolism, 4, 387-443, Academic Press, N. Y.

Munro H. N., r97o. Free amino acid pools and their regulation. In Munro H. N., Mammalian protein metabolism, 4, 299-386. Academic Press N. Y.

Norton B. W., Walker D. M., I97I. Nitrogen balance studies with the milk-fed lamb. 7 . Effect of age of the lamb. Br. J. Nutr., 26, I-6.

Patureau-Mrrand P., Prugnaud J., Pion R., I973. Influence de la supplémentation en acides aminés soufrés d'un aliment d'allaitement sur l'aminoacidémie. Estimation du besoin en méthionine du Veau préruminant. Ann. Biol. anim. Bioch. Biophys., 13, 225-246.

Patureau-Mirand P., Theriez M., Prugnaud J., I975. Infiuence de la nature des protéines alimentaires sur l'aminoacidémie de l'Agneau préruminant. Ann. Biol. anim. Bioch. Biophys., 15, 95-IOI. 
Pion R., 1976. Dietary effects and amino acids in tissues. In Cole D. J. A., Boorman K. N. Buttery P. J., Lewis D., Neale R. J., Swan H., Protein Metabolism and Nutrition, 259-277. Butterworths. Londres.

Potter E. L., Purser D. B., Bergen W. G., 1972. A plasma reference index for predicting limiting aminoacids of sheep and rats. J. Anim. Sci., 34, 660-67I.

Sснгмке R. T., I962. Adaptative characteristics of urea cycle enzymes in rat liver. J. Biol. Chem., 238, Tот 2-1018.

Theriez M., Patureau-Mirand P., Molenat G., 1977. Allaitement artificiel de l'Agneau. IV. Comparaison de différentes teneurs en matières azotées dans le lait de remplacement. Ann. Zootech., 26, 297-313.

WALKer D. M., I975. Miethionine supplementation of milk proteins for preruminant lambs. II. Effect on wool growth, live weight gain and body composition. Aust. J. Res., 26, 68 I-688.

Walker D. M., Faicheney G. J., 1964. Nitrogen balance studies with the milk fed lamb. 3 . Effect of different nitrogen intakes on growth and nitrogen balance. $B r . J$. Nutr., 18, 295-306. WALKER D. M., KIRK R. D., I 975 . Methionine supplementation of milk protein for preruminant lambs. I. Effect of protein concentration and source of carbohydrate on nitrogen balance. Aust. J. Agric. Res., 26, 673-679.

Walker D. M., Norton B. W., 197r. Nitrogen balance studies with the milk fed lamb. 9. Energy and protein requirements for maintenance, live weight gain and wool growth. $B v . J$. Nutr., 26, 1 5-29. 